Marquette University

e-Publications@Marquette

Exercise Science Faculty Research and

Publications

Exercise Science, Department of

$1-2016$

\title{
Survivors Speak: A Qualitative Analysis of Motivational Factors Influencing Breast Cancer Survivors' Participation in a Sprint Distance Triathlon
}

\author{
Karen Marie Robinson \\ Marquette University, karen.robinson@marquette.edu \\ Linda B. Piacentine \\ Marquette University, linda.piacentine@marquette.edu \\ Leslie J. Waltke \\ Aurora Health Care \\ Alexander V. $\mathrm{Ng}$ \\ Marquette University, alexander.ng@marquette.edu \\ Judy A. Tjoe \\ University of Wisconsin School of Medicine \& Public Health
}

Follow this and additional works at: https://epublications.marquette.edu/exsci_fac

Part of the Medicine and Health Sciences Commons

\section{Recommended Citation}

Robinson, Karen Marie; Piacentine, Linda B.; Waltke, Leslie J.; Ng, Alexander V.; and Tjoe, Judy A., "Survivors Speak: A Qualitative Analysis of Motivational Factors Influencing Breast Cancer Survivors' Participation in a Sprint Distance Triathlon" (2016). Exercise Science Faculty Research and Publications. 75.

https://epublications.marquette.edu/exsci_fac/75 


\title{
Survivors Speak: A Qualitative Analysis of Motivational Factors Influencing Breast Cancer Survivors' Participation in A Sprint Distance Triathlon
}

\author{
Karen M. Robinson \\ College of Nursing, Marquette University, \\ Milwaukee, WI \\ Linda B. Piacentine \\ College of Nursing, Marquette University, \\ Milwaukee, WI \\ Leslie J. Waltke \\ Department of Physical Therapy, Aurora Health Care, \\ Milwaukee, WI \\ Alexander V. Ng \\ Department of Exercise Science, Marquette University, \\ Milwaukee, WI
}


NOT THE PUBLISHED VERSION; this is the author's final, peer-reviewed manuscript. The published version may be accessed by following the link in the citation at the bottom of the page.

\author{
Judy A. Tjoe \\ University of Wisconsin School of Medicine \& Public Health, \\ Surgical Breast Oncology, Aurora Research Institute, \\ Aurora Health Care, \\ Milwaukee, WI
}

\begin{abstract}
Aims and objectives: To examine motivational factors influencing breast cancer survivors to participate in triathlon training, complete a triathlon and maintain an exercise thereafter.

Background: Routine exercise has been shown to improve quality of life and reduce recurrence for breast cancer survivors. Yet physical and psychological factors present barriers for initiating and maintaining an exercise routine. Research is limited in exploring factors of exercise motivation from the survivor's perspective.

Design: Qualitative design using focus groups and individual follow-up phone interviews to explore motivation for exercise initiation and maintenance.

Methods: One to two weeks after completing a triathlon, 11 breast cancer survivors who trained together participated in one of three focus groups to discuss their experience. Five months post triathlon 6 of the 11 participants were successfully contacted and phone interviews were conducted to explore exercise maintenance. Focus groups and interviews were analysed using content and thematic analysis.

Results: Five themes emerged (1) Champion for Exercise, (2) Part of a Team, (3) Everyone Had a Story, (4) Not Really Exercise and (5) What Do We Do Now? Overall, survivors recognised their need for lifestyle change (e.g. moving from a sedentary lifestyle to a more active one). More importantly, they identified the team approach to exercise initiation was crucial in their success in sustaining a behavioural change.

Conclusions: Emphasis needed on developing team exercise training programmes for survivors. Nurses can play a critical role in discussing with survivors, the benefits of exercise initiation and maintenance.

Relevance to clinical practice: Breast cancer survivors are hesitant to initiate routine exercise. Training with women who share a common lived experience increases the likelihood of success. Nurses are in a position to encourage breast cancer survivors to participate in group exercise programmes as a way to improve quality of life.

\section{What does this paper contribute to the wider global clinical} community?

- Motivation for lifestyle behavioural change among breast cancer survivors is multifaceted.

- Using exercise to improve the quality of life for breast cancer survivors can be achieved by applying a team training approach.
\end{abstract}

Environmental Toxicology, Vol 25, No. 1-2 (January 2016): pg. 247-256. DOI. This article is (C) Wiley and permission has been granted for this version to appear in e-Publications@Marquette. Wiley does not grant permission for this article to be further copied/distributed or hosted elsewhere without the express permission from Wiley. 
NOT THE PUBLISHED VERSION; this is the author's final, peer-reviewed manuscript. The published version may be accessed by following the link in the citation at the bottom of the page.

\section{Introduction}

Approximately one in eight women in the USA will develop breast cancer during their lifetime. Due largely to advancements in early detection and treatment options, it is estimated that $89 \%$ of women diagnosed with breast cancer will survive five years or more (www.cancer.gov). However, the cancer and treatments of surgery, chemotherapy, radiation therapy and/or hormone therapy cause fatigue, sleep disturbances, depression, weight gain, decreased cardiopulmonary function and impaired muscular function, which may continue after completion of treatment and negatively impact quality of life (QOL) for these women (Mustian et al. 2012, Balneaves et al. 2014).

Research has shown that various forms of exercise or increased physical activity post cancer treatment reduce symptoms and improves QOL for breast cancer survivors (Cho et al. 2012). Exercise is also associated with decreased risk of recurrence and breast cancer deaths. The level of prediagnosis physical activity has a near-linear relationship with survival after diagnosis (Urbscheit \& Brown 2013) and sustained moderate exercise after treatment is associated with improved breast cancer survival rates (Chen et al. 2011). High levels of physical activity after diagnosis are associated with improved survival rates (Bradshaw et al. 2014) even in women who were not active prior to diagnosis (Mason et al. 2013).

Despite the growing evidence that regular exercise reduces symptoms, improves physical fitness and $\mathrm{QOL}$ and lowers recurrence rate and all-cause mortality, the majority of breast cancer survivors do not exercise regularly. One study using accelerometry found that as few as $9 \cdot 2 \%$ of breast cancer survivors who were diagnosed more than five years prior meet the CDC guidelines for 150 minutes of moderate exercise per week (Loprinzi et al. 2013). Another retrospective selfreport study found that only $34 \%$ of women met recommended guidelines for exercise over the year prior to diagnosis and this number dropped to $21 \%$ at 10 years after treatment (Mason et al. 2013). Although the numbers are variable, most statistics show that the per cent meeting recommended exercise guidelines is low. To date, few studies have examined factors affecting exercise motivation,

Environmental Toxicology, Vol 25, No. 1-2 (January 2016): pg. 247-256. DOI. This article is (C Wiley and permission has been granted for this version to appear in e-Publications@Marquette. Wiley does not grant permission for this article to be further copied/distributed or hosted elsewhere without the express permission from Wiley. 
NOT THE PUBLISHED VERSION; this is the author's final, peer-reviewed manuscript. The published version may be accessed by following the link in the citation at the bottom of the page.

initiation and maintenance from the perspective of breast cancer survivors.

\section{Background}

Studies have shown that exercise is important in breast cancer survivors. Researchers have begun to examine barriers and facilitators of exercise initiation and maintenance after breast cancer treatment. Women studied five years after diagnosis report psychological, physical and environmental barriers to exercise, including lack of motivation, poor body image, co-morbidities, fatigue, employment and seasonal weather (Hefferon et al. 2013). Few studies of breast cancer survivors have integrated behaviour change theories to examine factors influencing exercise initiation and maintenance (Short et al. 2013). Improved levels of social support have been found to positively impact exercise in cancer survivors (Barber 2013). Readiness and intention to initiate and maintain exercise may be associated with exercise adherence (Husebø et al. 2013).

Most of the studies examining effects of exercise have focused on structured exercise in group fitness or home-based programmes (Carmichael et al. 2010). These group programmes are focused on instructing the individuals in a group setting, and have not addressed/examined the effects of exercise when the group participants are encouraged to work together as a team. One exception is 'dragon boat racing' which is a sport in which 22 people work together to paddle a large boat. Dragon boating was originally used to determine if repetitive exercise caused lymphoedema in high risk women (Harris 2012). Breast cancer survivors continue to enjoy this team exercise environment in an outdoor setting. Literature is rarely found that reports on recreational sports or outdoor activities in which anyone might be able to participate.

Triathlon is one recreational sport that has shown rapid growth in participation rates since debuting in the 2000 Olympic Games (http://www.usatriathlon.org). A triathlon is a multisport event that comprises cross-training with swimming, bicycling and running. Growth in triathlon participation includes women whose membership has increased from $27 \%$ in 2009 to $36.5 \%$ in 2013. (http://www.usatriathlon.org/about-multisport/demographics.aspx, 
NOT THE PUBLISHED VERSION; this is the author's final, peer-reviewed manuscript. The published version may be accessed by following the link in the citation at the bottom of the page.

accesssed10/17/2014). Triathlon events are often classified as sprint triathlons that include distances of approximately $500 \mathrm{~m}$ swimming, $20 \mathrm{~km}$ cycling and $5 \mathrm{~km}$ running. Triathlons for recreational athletes emphasise participation rather than competition. Sprint distance triathlons, while individually challenging, are an accessible goal for many recreational athletes. However, triathlon participation requires inordinate amounts of commitment and practice. Of the women who do participate it is unknown how many are breast cancer survivors, or how breast cancer survivors make the decision to participate.

The purpose of this qualitative study was to examine breast cancer survivors' motivation for participating in team triathlon training, completing a triathlon and sustained exercise thereafter. Two research questions formed the basis of this study, 'What factors influenced breast cancer survivors to initiate a triathlon training programme and to complete a triathlon? What effect would participating in triathlon training and competing in a triathlon have on breast cancer survivors' intent to maintain exercise?'

\section{Theoretical framework}

The Transtheoretical Model (TTM) of Change (Prochaska \& DiClemente 1983) has been used to examine change in health promoting behaviours such as exercise. Prochaska and DiClemente (1983) describe the act of behavioural change as a series of temporal stages through which one progresses. The critical assumption that underpins this model is that behavioural change does not occur instantaneously, but through a series of distinct, predictable stages: pre-contemplation, contemplation, preparation, action and maintenance that occur over time. In this model, change is not constantly linear; individuals may revert back into previous stages before forward progression for can be achieved (http://www.prochange.com/transtheoretical-model-of-behaviorchange). The stages of preparation, action and maintenance were the foci in this study of breast cancer survivors who participated in a triathlon.

According to Prochaska et al. (1992), during the preparation stage, one recognises and acknowledges that a health behavioural problem exists (e.g. sedentary lifestyle, overweight, etc.). They have 
made a decision to change and now seek assistance in making such a change. Progression into the action stage requires one to make behavioural modifications from former lifestyle and behaviours. Desire and commitment are crucial attributes to the success in this stage. Classification of being in the action stage is noted if one has 'successfully altered the [negative] behavior for a period of one day to six months' (Prochaska et al.1992, p,. 1104). Prochaska et al. (1992) describe the stage of maintenance as the period in which one works to avoid reverting back into undesired behaviour. This stage can be seen as life change. Maintaining a change in behaviour for at least six months is a criterion for maintenance stage. However, Short et al. (2013) noted that individuals studied using TTM demonstrated achieved significant positive behaviour change with interventions that lasted at least 12 weeks.

\section{Methods}

\section{Design}

A qualitative research design using focus groups was used for this study. This method was selected to gather team accounts of motivation to engage in a triathlon training programme, complete a sprint triathlon and maintain an exercise regimen thereafter. In the focus groups, breast cancer survivors discussed their lived experiences in achieving individual and team goals while completing 14-weeks of training and the triathlon. Furthermore, the usage of focus groups allowed the researchers the opportunity to capitalise on the group training concept inherent in doing a triathlon. Follow-up individual phone interviews were conducted five months post triathlon to examine maintenance of exercise regimens. Approval to conduct this study was granted by the authors' university institutional review board.

\section{Participants}

A group of female breast cancer survivors participated in a 14week individualised team triathlon training programme. The team was a medically supervised, sprint distance triathlon training programme developed by a physician-led team at a local health system. The

Environmental Toxicology, Vol 25, No. 1-2 (January 2016): pg. 247-256. DOI. This article is (C) Wiley and permission has been granted for this version to appear in e-Publications@Marquette. Wiley does not grant permission for this article to be further copied/distributed or hosted elsewhere without the express permission from Wiley. 
training was comprised of two supervised group sessions and three home-based sessions per week. The programme culminates with team participation in a sprint distance triathlon (Athleta Iron Girl: 0.5 mi swim, $12 \mathrm{mi}$ bike, $3.1 \mathrm{mi}$ run). Members of the triathlon training team who completed the sprint triathlon in the summer of $2013(n=37)$ were invited to participate in a focus group to discuss their experiences.

One to two weeks after completing the sprint triathlon, 11 of the 37 survivors who completed the training and triathlon consented to participate in one of three focus groups. The mean age of the women who participated in the focus groups was 50.9 (SD 7.1) years. To understand why women of various body types participate in the training team, focus groups were divided by BMI: two with a normal BMI (18.5-24.9), four with an overweight BMI (25-29.9) and five who had BMI classification of obese $(\geq 30)$. Women who declined to participate in the focus groups expressed disinterest or could not attend due to scheduling conflicts. Participants had a mean age at diagnosis of 51.5 years (7.08 SD). The women had been diagnosed with various stages of cancer ranging from Stage 0 to Stage IIIB. The treatment was diverse among the women including: radiation, chemotherapy and mastectomy with and without reconstruction. The average years of survivorship were five years (3.58 SD). Five months post triathlon, six of the 11 women who participated in the focus groups were successfully contacted and participated in individual phone interviews. The goal of the follow-up interviews was to determine if they were maintaining an exercise routine. Open-ended questions were asked regarding current exercise regimen and whether the training team had an influence on their exercise behaviour.

\section{Data collection}

Focus groups were audio taped for accuracy. The first two authors conducted the focus groups and took records noting participants' nonverbal behaviour. The first author led the focus group. Because the purpose of this study was to examine a breast cancer survivor's motivation to participate in training for and completing a triathlon, open-ended style of inquiry was used to gain insight. Questions were structured based on the Stages of Change Model. 
Specifically, the concepts of preparation and action guided the questions. For example, survivors were asked to 'Describe your exercise regimen prior to diagnosis' and 'prior to joining Team Phoenix [the triathlon training team]?' Other leading questions included 'Describe your experience as a member of Team Phoenix?'; 'Describe what helped you to continue with the triathlon?'; 'Describe any barriers you may have encountered?'.

Participants were encouraged to speak openly and freely regarding their experiences. No team coaches or medical staff were involved in the focus groups. The length of each focus group varied (30-45 minutes) with some groups being more verbal than others. Probing questions were also used when needed to stimulate more indepth discussions among the group and to maintain/adhere to the purpose of the study.

\section{Analysis}

The audio tapes from each focus group were transcribed, verbatim and reviewed by the first two authors for accuracy. Using content and thematic analysis, the first two researchers independently reviewed and analysed the transcriptions and coded like statements and phrases. The researchers separately identified major themes and sub-themes in the data. Each researcher checked the transcripts for accuracy by comparing the written transcripts and field notes to the taped audio of each focus group. After the initial individual evaluation, the researchers met to review the statements and themes. Transcripts were again reviewed seeking evidence of the themes. Discussion ensued until mutual agreement was achieved regarding themes and sub-themes.

The individual five-month follow-up phone interviews were also audio taped and transcribed verbatim. The first two authors followed the same method of analysis as described above for these transcriptions. 
NOT THE PUBLISHED VERSION; this is the author's final, peer-reviewed manuscript. The published version may be accessed by following the link in the citation at the bottom of the page.

\section{Results}

Content analysis of the focus groups transcripts yielded five themes or factors which influenced the women's motivation for initiation and completion of triathlon training: Champion for Exercise, Part of a Team, Everyone Had a Story, Not Really Exercise and What Do We Do Now? (Fig. 1.).

\section{Champions for Exercise}

- External Motivation

- Internal Motivation

\section{Part of a Team}

Everyone Had a Story

\section{Not Really Exercise}

\section{What do we do now?}

Figure 1. Motivational themes influencing behavioural change.

\section{Champion for exercise}

Prior to joining the training team, the majority of the participants admitted that they had no routine exercise regimen. In fact, one participant openly admitted, 'Even before cancer I would have never thought about ever doing this [exercise/train].' The participants all spoke of factors that influenced their decisions while they contemplated engaging in some type of exercise regimen and joining the training team. The factors the survivors described as instrumental to their exercise choices were both internal and external influences. 
NOT THE PUBLISHED VERSION; this is the author's final, peer-reviewed manuscript. The published version may be accessed by following the link in the citation at the bottom of the page.

\section{External motivation}

The survivors reported outside motivators including familial encouragement as influences. 'My sister... our mom died of breast cancer at $42 .^{\prime}$

Others mentioned that survivors from previous cohorts of the triathlon training programme had an impact on their decision to join. 'People from last year just really inspired.'

Despite being apprehensive, some women took the advice of health care providers and made the decision to commit to the triathlon training. 'My gynecologist handed me a flyer with Team Phoenix on it and he said, 'You should try this triathlon.' I thought he was nuts!' 'I'm so thankful she [her surgeon] encouraged me; I want to live a lot more years.'

\section{Internal motivation}

Many of the participants spoke to the fact that internally, they knew they had to make a health behavioural change since being diagnosed with cancer. Many saw it as a way of having some control over the disease asking 'what can I do to be proactive about my health.' 'I need to find a way to keep fighting it [cancer]. So I went in [to the training] thinking of it as way to fight the cancer.'

One survivor spoke about being scared after she heard, 'every 13 pounds that you are overweight there is an $11 \%$ chance of the cancer reoccurring;' 'and that just scared me. That really scared me.' So she knew she had to do something.

\section{Part of a team}

Once survivors in this study had made the decision to join the triathlon training, they then spoke about the experience during training (preparation \& action). Being a part of team is what many of the women found they needed to be a successful member of the team. Success was defined as getting through the 14-week training and attempting to complete the sprint triathlon. 
NOT THE PUBLISHED VERSION; this is the author's final, peer-reviewed manuscript. The published version may be accessed by following the link in the citation at the bottom of the page.

'The group support is what we need.' During training, women reported that being part of the team kept them encouraged, sustained their involvement and eventually assisted them in completing the race. 'The camaraderie is what gets you through it. Where else can you go to have that kind of support?' Furthermore, 'we are accountable for one another.' When describing the impact of being a member of the triathlon training team, one survivor tearfully said, 'I prayed to God please just send me a workout partner. He sent me a team. This is my blessing.'

Even though all the survivors in this study reported a feeling part of a team, we found that some did not feel this sense of belonging immediately. 'I'm a little slow to warm up to people. I'm a little more guarded and I did not think I was going to enjoy it [the training] as much as I did.' Another member of the Team agreed in saying she 'was more of a loner in the beginning.' Yet, by the end of the 14 week training they too felt the solidarity.

\section{Everyone had a story}

One factor that the women unanimously agreed was a positive motivation was the fact that they all shared the lived experience of being diagnosed with breast cancer. More importantly, they shared survivorship. This commonality allowed everyone to be relatable. There was a night during the training sessions, instead of working out, the trainers encouraged all to share their breast cancer journey. 'It was nice just being with women again with similar back stories. So you know they get it.' Another participate noted, 'I think that was very important just to see everyone else was in the same predicament that I've been.' 'There was always someone with similar background; similar story.'

This shared experience of being among other breast cancer survivors was important when the women discussed being in a gym environment for training. They spoke of the physical changes related to radiation, chemotherapy and surgery (mastectomies) and how the disfigurement from treatment makes it difficult to feel comfortable in a public place such as a gym. One survivor recalled, 'I wasn't confident. When I swam at the gym, I would be very self-conscious of changing in the changing room because I didn't want anyone to see.' She 
admitted to putting her bra on 'in the shower' to avoid others looking at her scars.

Therefore, being surrounded by others with similar physical changes made simple tasks like changing into workout clothes easier. 'You're not embarrassed about it [mastectomy] in front of everybody else. I think that was good for me.' Others agreed, 'Inhibitions went out the window. There was no hiding anything.'

\section{Not really exercise}

The attitude and support of the members of the research team, specifically the coaches were also valued as having a major impact on carry out the training and eventually the triathlon. They noted that the trainers made training fun. 'I guess it wasn't just work; it was fun.' The trainers offered a variety of sites for training which was appreciated by the team. It 'was nice to see different places [around the city]. I saw places I did not know existed. Nice to give people a variety because we live in all different areas of the city.' The majority of the participants, who had BMIs of $\geq 25$, noted how impressed they were with their progress over time. 'It was such a gradual transition that you do not realize that you were getting better.' Furthermore, the women were often amazed at their progress. 'I was just surprised that my body was able to handle everything that I did. I didn't think that I would be able to endure everything my body did.'

\section{What do we do now?}

Regardless of BMI, the survivors in this study wanted to keep the exercise momentum moving forward (progressing towards maintenance stage). Currently, there is no formalised alumni group for members of the training team. Once the survivors have completed the sprint triathlon, their cohort is completed. Therefore, they asked, 'What do we do now?' They spoke of needing to find ways to 'keep yourself mentally in the game [exercise].' They knew all too well how easy it could be for them to revert back to their sedentary lifestyles. 'If you have some event that you're always training for, it will be harder to fall into the TV rut.' Now that the 14 weeks of training and the 
NOT THE PUBLISHED VERSION; this is the author's final, peer-reviewed manuscript. The published version may be accessed by following the link in the citation at the bottom of the page.

triathlon were completed, many spoke of making 'your own new normal' in regards to developing and maintaining an exercise regime.

Because of the bonds and friendships that had developed from this training, the majority of the survivors wanted to continue to exercise together. 'We have enough participants to do something like an alumni.'

\section{Post-interview follow-up}

Because of the lack of research related to maintenance after exercise initiation among breast cancer survivors, the investigators called focus group participants from the triathlon training team approximately five months after completing the triathlon. Of the six successfully contacted, $100 \%$ indicated they were continuing to exercise at a level above their usual exercise regimen prior to triathlon training. It should be noted than the majority of these women originally had sedentary lifestyles prior to diagnosis, treatment and joining the team.

Participants noted various barriers to continuing the level of exercise they once experienced as a member of the triathlon team. Many indicated a desire to exercise more, but described barriers due to work, cold weather and difficulty with location of workouts. 'I just don't like to get out in the cold weather is part of it [the reason for limited exercise].' 'I like to do a lot of my activities outside and now that being cold. I just really don't like going to the gym; but, I have to force myself 'cause I know it's necessary.' 'I still walk. Well, except for now, during the cold spell here, I was walking on my half an hour lunch breaks and my 15 minutes breaks as well.'

Most women continued their relationships with other members of the training team and felt these relationships helped them to exercise at higher levels. The women indicated that the team had changed their lives and they now felt exercise was necessary. Some even took on the role of motivating their family and others to exercise. 'My family members have joined with me; two of them.' 'Team phoenix has become the family I never really had the support group I ever had.' 'Um..., they changed my life completely. If I don't talk or do something related to Team Phoenix regularly, I feel lost.' 
NOT THE PUBLISHED VERSION; this is the author's final, peer-reviewed manuscript. The published version may be accessed by following the link in the citation at the bottom of the page.

\section{Discussion}

This study examined the motivations of breast cancer survivors to participate in a medically supervised team training programme and sprint distance triathlon. A Transtheoretical Model of Change approach was used. The survivors, in this study, moved through the stages of change (preparation, action, and maintenance) in an effort to make improvements in a specific health behaviour (exercise). They acknowledged the need for a lifestyle behaviour change and complete a triathlon with the help of a supportive training team. The findings provide insight into how the individual survivor works in a group setting and is motivated to maintain regular exercise. This is the first study to look at this type of goal oriented team training programme. Understanding motivations of the women who participated is important in understanding how to help others to take action.

In a similar study, Balneaves et al. (2014) reported on a 24week weight loss lifestyle intervention which included diet education along with and 150 minutes/week of moderate exercise for breast cancer survivors. Both the lifestyle intervention and the triathlon studies encouraged home-based exercise in addition to twice-a-week supervised exercise sessions. The weight loss programme included supervised physical activity sessions in a research laboratory (Campbell et al. 2012), while the triathlon training took place in community locations including area parks, pools and lakes. Although the lifestyle study activity was restricted to activities in the lab, the triathlon training had varied exercises of swimming, biking, running and core strength activities. The triathlon group participants reported that the variety in exercises and locations enhanced their experience and kept them interested.

Female breast cancer survivors who completed the lifestyle study intervention were interviewed to determine positive and negative aspects of the intervention (Balneaves et al. 2014). Women in the study reported how they felt safe exercising in the environment with other breast cancer survivors and with professionals who could prevent them from doing exercises that would be harmful. The women felt better with exercise and were inspired by and had fun with their like-minded peers and with professionals who understood their cancer

Environmental Toxicology, Vol 25, No. 1-2 (January 2016): pg. 247-256. DOI. This article is (C Wiley and permission has been granted for this version to appear in e-Publications@Marquette. Wiley does not grant permission for this article to be further copied/distributed or hosted elsewhere without the express permission from Wiley. 
experience. The women also noted they were motivated to exercise because they were concerned about chemotherapy and wanted to improve their own health; they expressed sadness when the programme ended. These findings are congruent with findings from this study of triathlon participants.

Although the lifestyle intervention and the triathlon studies had many similar findings, a major difference was the strong camaraderie described by participants in the triathlon training, which is likely due to the team cohesiveness and a common goal. The triathletes discussed strong bonds with the other team members which led to them exercising together outside of the scheduled team practices. The team training concept in exercise interventions for breast cancer survivors is uncommon in the literature, with the only similar training being that of dragon boat racing. McDonough et al. (2010) described a dragon boat team-oriented recreational exercise programme. A dragon boat is a large 22-person boat in which paddlers of different abilities stroke in rhythm to a drumbeat. No prior experience is required to join a team and paddlers of all abilities work together to race the boat. The triathlon team is similar in being a team training event, but different in the fact that triathletes independently complete the race, as opposed to the paddlers finishing together. A comparison of the dragon boat team and the triathlon team is presented in Table 1.

Table 1. Comparison of team sports: triathlon and dragon boat racing

\begin{tabular}{|c|c|c|}
\hline Categories & Triathlon participation & Dragon boat racing \\
\hline Activities & $\begin{array}{l}\text { Swim, Bike, Run } \\
\text { Independent in a group }\end{array}$ & $\begin{array}{l}\text { Paddle } \\
\text { Dependent with the group }\end{array}$ \\
\hline Group Training & $\begin{array}{l}\text { Twice per week for } \\
14 \text { weeks }\end{array}$ & Twice per week for 12 weeks \\
\hline & $\begin{array}{l}\text { Additional at-home } \\
\text { activities }\end{array}$ & \\
\hline Location & Various parks, pools, gyms & River/lake \\
\hline Group environment & $\begin{array}{l}\text { Positive environment } \\
\text { Focus on activity not } \\
\text { disease } \\
\text { Similar stories of breast } \\
\text { cancer }\end{array}$ & $\begin{array}{l}\text { Positive environment } \\
\text { Focus on activity not disease } \\
\text { Shared understanding of breast } \\
\text { cancer }\end{array}$ \\
\hline $\begin{array}{l}\text { Measures of } \\
\text { performance }\end{array}$ & Individual participation & Group racing \\
\hline
\end{tabular}

Environmental Toxicology, Vol 25, No. 1-2 (January 2016): pg. 247-256. DOI. This article is (C Wiley and permission has been granted for this version to appear in e-Publications@Marquette. Wiley does not grant permission for this article to be further copied/distributed or hosted elsewhere without the express permission from Wiley. 
NOT THE PUBLISHED VERSION; this is the author's final, peer-reviewed manuscript. The published version may be accessed by following the link in the citation at the bottom of the page.

A supportive group environment with women having similar survivor stories and focused on a positive activity was important to both triathletes and dragon boat racers. Paddlers found team participation was a positive experience that focused on the activity rather than dwelling on the cancer (Unruh \& Elvin 2004). Dragon boat paddlers have been found to have improved social relations and social support from the activity (McDonough et al. 2011). Breast cancer survivors who dragon boat find that fellow paddlers understand exactly how you feel and they do not have to explain themselves (Sabiston et al. 2007). They feel connected within the team (Unruh \& Elvin 2004). Women working together towards participating in the triathlon also felt they had shared stories to tell and telling them to each other added to feelings of support. Triathletes noted that the other team members' support helped them to be comfortable with themselves and their body image. Body images has been found to be important as poor body images leads to decreased physical activity in breast cancer survivors (Charlier et al. 2012). The importance of a positive group environment by women focused on an activity with other breast cancer survivors is found in both triathlon and dragon boat racing. The support of other triathletes was critical to the success of the individual in the team.

In this study, we also learned that the women valued support received from others who were not part of the team, including their medical providers. Similar findings were reported by Jones et al. (2005) who found that women were influenced by their oncologist to exercise. Other studies have found friends and family as important motivators to exercise (Husebø et al. 2014) sometimes through a sense of companionship (Barber 2013).

Breast cancer survivors have also noted the importance of control in their lives. Charlier et al. (2012) studied physical activity in women after breast cancer treatment and found that women recently treated engaged in more physical activity if they felt they had more control. Dragon boat racers noted feelings of control with being active and found it to be important after the perceived lack of control with cancer treatment (Sabiston et al. 2007). The women find they have increased self-confidence and that they regain control of their lives (Unruh \& Elvin 2004). Triathletes also talked about increasing control

Environmental Toxicology, Vol 25, No. 1-2 (January 2016): pg. 247-256. DOI. This article is (C Wiley and permission has been granted for this version to appear in e-Publications@Marquette. Wiley does not grant permission for this article to be further copied/distributed or hosted elsewhere without the express permission from Wiley. 
over their cancer when exercising. Breast cancer survivors have felt loss of control in their lives and improved control when exercising.

To date, few exercise intervention studies have examined longterm changes in behaviour (maintenance). In this study, we found that although participants decreased their overall exercise intensity post triathlon compared to rigorous triathlon training, the exercise levels were still above their baseline status approximately five months after completing the triathlon. The literature supports that a behavioural intervention of more than 12 weeks does lead to sustained, positive change in exercise behaviour (Short et al. 2013). Others have reported that older breast cancer survivors do not use social processes to engage others in exercise (Loprinzi \& Cardinal 2013). Notably, triathlon team participants described seeking out others to exercise with them after the triathlon. Social engagement could be an important element to maintaining increased physical activity levels in this population who appear to benefit from group support.

\section{Conclusion}

Consistent with Prochaska and DiClemente's Theoretical Model (1983), our relatively younger group of survivors prepared to exercise with the team and took action to complete a triathlon training programme and participate in a sprint distance triathlon. Some of the survivors reported being in the maintenance phase by adapting and sustaining an exercise regimen into their lifestyles post triathlon. The findings from this study demonstrate the effectiveness of this model in eliciting positive behavioural change among breast cancer survivors.

These findings are also important as many survivors may not know how to initiate exercise. Loprinzi and Cardinal (2013) examined exercise behaviours in older breast cancer survivors and found that many did not have friends who exercised with them and lacked skills for enlisting social support for exercise. This inability to enlist social support suggests the importance of the team training programmes. Team participation in a supportive social environment is a promising approach to improving exercise in breast cancer survivors. In addition, the majority of the participants in this study had completed cancer treatment prior to the completion of the triathlon. Research is needed

Environmental Toxicology, Vol 25, No. 1-2 (January 2016): pg. 247-256. DOI. This article is (C Wiley and permission has been granted for this version to appear in e-Publications@Marquette. Wiley does not grant permission for this article to be further copied/distributed or hosted elsewhere without the express permission from Wiley. 
to examine exercise interventions for women with breast cancer prior to, during and continuing after treatment.

The participants of this study were younger and Caucasian; thus, the study lacks generalisability. Research is needed that includes breast cancer survivors from older and under-represented backgrounds. Breast cancer survivors, in this study, related individual and environmental factors involved in initiating triathlon training with a team. They also spoke to the difficulties of maintaining such level of training. Further research is needed to further examine factors impacting exercise maintenance in breast cancer survivors.

Although triathlon is a unique form of exercise that may not be attractive or even suitable for some survivors, this study demonstrates the inherent value of group/team exercise to sustain motivation and engagement in group activities. Less strenuous activities (e.g. brisk walking and low aerobic exercises) may be more appealing and shown to be beneficial to breast cancer survivors (Galantino et al. 2007, Luoma et al. 2014, Trinh et al. 2014, Vallance et al. 2014). The themes found in this study may translate to other forms of activities conducted in a group environment. Future research examining other methods of group/team exercise is necessary.

\section{Relevance to clinical practice}

The findings from this study demonstrate to nurses and other health care providers the importance of a supportive training team and the willingness of survivors to improve QOL through exercise. Furthermore, it provides insight into the factors influencing motivational maintenance and barriers related to team goal oriented exercise. Because we know of the benefits of exercise for breast cancer survivors, health care providers who care for breast cancer patients should discuss exercise with patients with the goal of longterm maintenance of recommended levels of exercise. The implementation of a behaviour change model can be beneficial to the development of more programmes geared towards improving QOL for breast cancer survivors' pre- and post treatment.

\section{Acknowledgements}

Environmental Toxicology, Vol 25, No. 1-2 (January 2016): pg. 247-256. DOI. This article is (C) Wiley and permission has been granted for this version to appear in e-Publications@Marquette. Wiley does not grant permission for this article to be further copied/distributed or hosted elsewhere without the express permission from Wiley. 
NOT THE PUBLISHED VERSION; this is the author's final, peer-reviewed manuscript. The published version may be accessed by following the link in the citation at the bottom of the page.

The triathlon team was developed and led by Dr. Judy Tjoe and Leslie Waltke. They are instrumental in the continued success of the programme. The authors would like to acknowledge and thank the resilient survivors who participated in our focus groups and the follow-up phone calls.

\section{Contributions}

Study design: KMR, LBP, LJW, AVN, JAT; Data collection and analysis: KMR, LBP; Manuscript preparation: KMR, LBP, LJW, AVN, JAT.

\section{Funding}

Kohl's Cares/American Cancer Society, Aurora Research Institute, Vince Lombardi Cancer Research Foundation/Aurora Health Care.

\section{Conflicts of interest}

The authors have no conflicts of interest to disclose.

\section{References}

Balneaves L, Van Patten C, Truant TO, Kelly M, Neil S \& Campbell K (2014) Breast cancer survivors' perspectives on a weight loss and physical activity lifestyle intervention. Supportive Care in Cancer 22, 20572065.

Barber FD (2013) Effects of social support on physical activity, self-efficacy, and quality of life in adult cancer survivors and their caregivers. Oncology Nursing Forum 40, 481-489.

Bradshaw PT, Ibrahim JG, Khankari N, Cleveland RJ, Abrahamson PE, Stevens J, Satia JA, Teitelbaum SL, Neugut AI \& Gammon MD (2014) Postdiagnosis physical activity and survival after breast cancer diagnosis: the Long Island Breast Cancer Study. Breast Cancer Research and Treatment 145, 735-742.

Campbell KL, Van Patten CL, Neil SE, Kirkham AA, Gotay CC, Gelmon KA \& McKenzie DC (2012) Feasibility of a lifestyle intervention on body weight and serum biomarkers in breast cancer survivors with overweight and obesity. Journal of the Academy of Nutrition and Dietetics 112, 559-567.

Carmichael AR, Daley AJ, Rea DW \& Bowden SJ (2010) Physical activity and breast cancer outcome: a brief review of evidence, current practice and future direction. European Journal of Surgical Oncology 36, 11391148.

Environmental Toxicology, Vol 25, No. 1-2 (January 2016): pg. 247-256. DOI. This article is (C) Wiley and permission has been granted for this version to appear in e-Publications@Marquette. Wiley does not grant permission for this article to be further copied/distributed or hosted elsewhere without the express permission from Wiley. 
NOT THE PUBLISHED VERSION; this is the author's final, peer-reviewed manuscript. The published version may be accessed by following the link in the citation at the bottom of the page.

Charlier C, Van Hoof E, Pauwels E, Lechner L, Spittaels H, Bourgois J \& De Bourdeaudhuij I (2012) Treatment-related and psychosocial variables in explaining physical activity in women three weeks to six months post-treatment of breast cancer. Patient Education and Counseling 89, 171-177.

Chen X, Lu W, Zheng W, Gu K, Matthews CE, Chen Z, Zheng Y \& Shu XO (2011) Exercise after diagnosis of breast cancer in association with survival. Cancer Prevention Research 4, 1409-1418.

Cho MH, Dodd MJ, Cooper BA \& Miaskowski C (2012) Comparisons of exercise dose and symptom severity between exercisers and nonexercisers in women during and after cancer treatment. Journal of Pain \& Symptom Management 43, 842-854.

Galantino ML, Cannon N, Hoelker T, Iannaco J \& Quinn L (2007) Potential benefits of walking and yoga on perceived levels of cognitive decline and persistent fatigue in women with breast cancer. Rehabilitation Oncology 25, 3-16.

Harris SR (2012) "We're All in the Same Boat": a review of the benefits of dragon boat racing for women living with breast cancer. EvidenceBased Complementary and Alternative Medicine, 2012, 1-6.

Hefferon K, Murphy H, McLeod J, Mutrie N \& Campbell A (2013) Understanding barriers to exercise implementation 5-year post-breast cancer diagnosis: a large-scale qualitative study. Health Education Research 28, 843-856.

Husebø AML, Dyrstad SM, Søreide JA \& Bru E (2013) Predicting exercise adherence in cancer patients and survivors: a systematic review and meta-analysis of motivational and behavioural factors. Journal of Clinical Nursing 22, 4-21.

Husebø AML, Karlsen B, Allan H, Søreide JA \& Bru E (2014) Factors perceived to influence exercise adherence in women with breast cancer participating in an exercise programme during adjuvant chemotherapy: a focus group study. Journal of Clinical Nursing 24, 500-511.

Jones LW, Courneya KS, Fairey AS, Mackey JR (2005) Does the Theory of Planned Behavior Mediate the Effects of an Oncologist's Recommendation to Exercise in Newly Diagnosed Breast Cancer Survivors? Results from a Randomized Controlled Trial. Health Psychology 24(2), 189-197.

Loprinzi P \& Cardinal B (2013) Self-efficacy mediates the relationship between behavioral processes of change and physical activity in older breast cancer survivors. Breast Cancer 20, 47-52.

Loprinzi P, Lee H \& Cardinal B (2013) Objectively measured physical activity among US cancer survivors: Considerations by weight status. Journal of Cancer Survivorship 7, 493-499.

Environmental Toxicology, Vol 25, No. 1-2 (January 2016): pg. 247-256. DOI. This article is (C Wiley and permission has been granted for this version to appear in e-Publications@Marquette. Wiley does not grant permission for this article to be further copied/distributed or hosted elsewhere without the express permission from Wiley. 
NOT THE PUBLISHED VERSION; this is the author's final, peer-reviewed manuscript. The published version may be

accessed by following the link in the citation at the bottom of the page.

Luoma M-L, Hakamies-Blomqvist L, Blomqvist C, Nikander R, GustavassonLilius M \& Saarto $L$ (2014) Experiences of breast cancer survivors participating in a tailored exercise intervention- a qualitative study. Anticancer Research 34, 1193-1200.

Mason C, Alfano CM, Smith AW, Wang CY, Neuhouser ML, Duggan C, Bernstein L, Baumgartner KB, Baumgartner RN, Ballard-Barbash R \& McTiernan A (2013) Long-term physical activity trends in breast cancer survivors. Cancer Epidemiology Biomarkers \& Prevention 22, 11531161.

McDonough MH, Sabiston CM, Sedgwick WA \& Crocker PR (2010) Changes in intrinsic motivation and physical activity among overweight women in a 12-week dragon boat exercise intervention study. Women in Sport \& Physical Activity Journal 19, 33.

McDonough MH, Sabiston CM \& Ullrich-French S (2011) The development of social relationships, social support, and posttraumatic growth in a dragon boating team for breast cancer survivors. Journal of Sport and Exercise Psychology 33, 627.

Mustian KM, Sprod LK, Janelsins M, Peppone LJ \& Mohile S (2012) Exercise recommendations for cancer-related fatigue, cognitive impairment, sleep problems, depression, pain, anxiety, and physical dysfunction: a review. Oncology Hematology Review 8, 81-88.

Prochaska JO \& DiClemente CC (1983) Stages and processes of self-change of smoking: toward a comprehensive model of change. Journal of Consulting and Clinical Psychology 51, 390-395.

Prochaska JO, DiClemente CC \& Norcross JC (1992) In search of how people changes: applications to addictive behaviors. American Psychologist 47, 1102-1114.

Sabiston CM, McDonough MH \& Crocker PR (2007) Psychosocial experiences of breast cancer survivors involved in a dragon boat program: exploring links to positive psychological growth. Journal of Sport and Exercise Psychology 29, 419-438.

Short C, James E, Stacey F \& Plotnikoff R (2013) A qualitative synthesis of trials promoting physical activity behaviour change among posttreatment breast cancer survivors. Journal of Cancer Survivorship 7, 570-581.

Trinh L, Mutrie N, Campbell AM \& Crawford JJ (2014) Effects of supervised exercise on motivational outcomes in breast cancer survivors at 5-year follow-up. European Journal of Oncology Nursing 18, 557-563.

Unruh AM \& Elvin N (2004) In the eye of the dragon: women's experience of breast cancer and the occupation of dragon boat racing. Canadian Journal of Occupational Therapy 71, 138-149.

Environmental Toxicology, Vol 25, No. 1-2 (January 2016): pg. 247-256. DOI. This article is @ Wiley and permission has been granted for this version to appear in e-Publications@Marquette. Wiley does not grant permission for this article to be further copied/distributed or hosted elsewhere without the express permission from Wiley. 
NOT THE PUBLISHED VERSION; this is the author's final, peer-reviewed manuscript. The published version may be accessed by following the link in the citation at the bottom of the page.

Urbscheit N \& Brown K (2013) The association between physical activity and breast cancer recurrence and survival [meta-analysis]. Current Nutrition Reports 3, 16-21.

Vallance J, Lavallee C, Culos-Reed N \& Trudeau M (2014) Rural and small town breast cancer survivors' preferences for physical activity. International Journal of Behavioral Medicine 20, 522-528. 